\title{
International Missions to the Moon: Space Exploration Goals, Programs and Economics
}

\author{
Venkatesan Sundararajan * \\ Washington Mutual Bank, Irvine, CA, 92630
}

\begin{abstract}
The Moon is soon to become an active space exploration destination. It is viewed as the necessary step for sustained robotic and human exploration of the solar system. The United States is embarked on the Moon exploration as part of the Vision for Space Exploration (VSE) mandate to extend human presence in Moon, Mars and beyond. The Robotic Lunar Exploration Program (RLEP) is a sequence of missions currently in progress intended to meet the objectives which enable a successful human return to the Moon in 2015-2020. The European Space Agency (ESA) is nearing completion of its SMART-1 orbiter mission to the Moon and the Aurora Space Exploration Program, the European framework for space exploration has identified Moon as an important stepping stone for broader robotic and human exploration of the solar system. Russia is planning a new "Luna-Glob" mission as part of its formal space plan conceived with a view to understand the origin of the EarthMoon system. Emerging space powers, Japan, China and India are all preparing independent Lunar orbiter missions as a necessary step in their quest for implementing sustainable deep space missions. This paper is a study in understanding the overall space exploration policy goals, programs being implemented to achieve these goals and their science objectives and the space economics involved. The international cooperation among the space faring nations in their lunar exploration programs is also outlined.
\end{abstract}

\section{Introduction}

$\mathrm{T}$ HE Lunar exploration is undergoing a renaissance as there is renewed interest in lunar exploration by international space agencies. Unlike the previous Moon missions, the current interest is driven by a keen desire to establish sustainable robotic and human exploration programs as part of a long term goal of comprehensive solar system exploration.

The successful completion of the European Space Agency's SMART-1 mission to the Moon with a spectacular impact on the near side of the lunar surface on September 3, 2006 after sixteen months of scientific data collection heralds the beginning of the lunar exploration revival.

The United States is leading the international lunar exploration programs propelled by its Vision for Space Exploration (VSE) mandate that calls for a robust, sustainable and affordable program to enable human exploration of Mars and beyond. The lunar exploration is the necessary first step in achieving the long term space exploration goals. The European space exploration framework, Aurora program, also envisions Moon exploration as part of its long term solar system exploration goals.

Emerging space powers, China, Japan and India are also planning Moon probes within this decade to establish themselves as capable of carrying out deep space missions and in preparation for future lunar resource exploitation. Russia is planning an ambitious Moon impact mission with an aim to revive the planetary exploration program after decades of negligence due to budget constraints.

The global interest in the Moon exploration is driven primarily by the following policy goals:

i) Understanding the origin and composition of Moon is the scientific gateway to gain insights on the formation and evolution of the inner solar system and the early crusts of Earth and Mars.

ii) Moon serves as a good destination for humans leaving low-Earth orbit to practice techniques that could eventually be used on Mars exploration.

iii) Moon is the first stepping stone for aspiring nations establishing robotic planetary exploration programs. ${ }^{1}$

\footnotetext{
${ }^{*}$ Senior Member, AIAA
} 
Exploiting the unique characteristics of the Moon can provide great benefits to mankind in areas such as establishing a lunar telecommunications base as a link between Earth and solar system exploration probes, both robotic and human; Moon based solar power stations and utilization of lunar surface Helium as energy source; lunar surface mining; establishing astronomical observatories and for future commercial ventures.

\begin{tabular}{|c|c|}
\hline \multicolumn{2}{|c|}{ Summary of Lunar Exploration Benefits } \\
\hline $\begin{array}{l}\text { Learning about the Formation and Evolution of Planets } \\
\text { - Understanding how rocky planets form and evolve } \\
\text { - Evolution of the Earth-Moon system } \\
\text { - Signatures of accretional process in the inner planets } \\
\text { - Studying comparative geophysical process } \\
\text { Using the Moon as a Collector of Extraterrestrial Samples } \\
\text { - Regolith Sample of the solar wind's history } \\
\text { - Samples of icy cometary deposits over the last } 10^{8} \text { years } \\
\text { - Samples from the early Earth, inner planets, asteroids and } \\
\text { comets } \\
\text { - Lunar surface exploration for minerals and energy sources }\end{array}$ & $\begin{array}{l}\text { Preparing for Future Lunar and Planetary Exploration } \\
\text { - Survey of lunar resources (minerals, volatiles, lighting) } \\
\text { - High-resolution studies for landing sites/ outposts } \\
\text { - Testbed for advanced technologies } \\
\text { - Environmental studies in support of human exploration } \\
\text { - Coordination between international Moon missions } \\
\text { Social Benefits } \\
\text { - Technology challenges and jobs in industry } \\
\text { - Inspiration for the general public and youth for knowledge, } \\
\text { science, technology and innovation } \\
\text { - Future commercial opportunities } \\
\text { - Moon base as a refuge for humans in case of a global } \\
\text { nuclear or asteroid catastrophe }\end{array}$ \\
\hline
\end{tabular}

The current decade (2005-2015) could be termed as the International Lunar Decade given the array of planned robotic missions to the Moon by the world's leading space agencies. NASA's primary goal to send humans back to the Moon by 2020 as part of the VSE mandate is poised to spur renewed interest in lunar exploration by global scientific establishments and political leadership.

The establishment of the International Lunar Exploration Working Group (ILEWG) which brings together the various space agencies around the world serves as the main forum for the coordination of international lunar initiatives for cooperation and collaboration among the different national lunar exploration programs and in preparing for the next steps in Moon exploration.

The major international missions to the Moon currently underway are detailed in the following sections. The table below provides a synopsis for these missions.

International Missions to the Moon

\begin{tabular}{|c|c|c|c|c|c|c|c|c|c|}
\hline No. & $\begin{array}{l}\text { International } \\
\text { Moon Mission }\end{array}$ & Space Agency & $\begin{array}{l}\text { Primary } \\
\text { Mission } \\
\text { Cost (\$) }\end{array}$ & $\begin{array}{l}\text { Launch } \\
\text { Date }\end{array}$ & $\begin{array}{l}\text { Primary } \\
\text { Mission } \\
\text { Period }\end{array}$ & $\begin{array}{l}\text { Launch } \\
\text { Weight } \\
(\mathrm{kg})\end{array}$ & $\begin{array}{l}\text { Payload } \\
\text { Weight } \\
\text { (kg) }\end{array}$ & Orbit & Mission Highlights \\
\hline 1 & SMART-1 & $\begin{array}{l}\text { European } \\
\text { Space Agency } \\
\text { (ESA) }\end{array}$ & $\begin{array}{l}\sim \$ 150 \\
\text { Million }\end{array}$ & $\begin{array}{l}\text { Sept. 27, } \\
2003\end{array}$ & \begin{tabular}{|l} 
Jan. 2005 - \\
Sept. 2006
\end{tabular} & 367 & 19 & $\begin{array}{l}\text { Polar } \\
\text { Elliptical } \\
(500-3 k \mathrm{~km}) \\
\end{array}$ & $\begin{array}{l}\text { 1) Europe's first mission to the Moon } \\
\text { 2) Successfully tested the solar electric } \\
\text { propulsion ion engine system }\end{array}$ \\
\hline 2 & SELENE & JAXA, Japan & & 2007 & $>12$ Months & 2885 & 270 & $\begin{array}{l}\text { Polar } \\
\text { Circular } \\
(100 \mathrm{~km})\end{array}$ & $\begin{array}{l}\text { 1) To carry two relay and radio astronomy } \\
\text { satellites } \\
\text { 2) Chief focus is to map sub-surface, mineral } \\
\text { composition and observe gravity fields }\end{array}$ \\
\hline 3 & CHANG'E-1 & CNSA, China & $\begin{array}{l}\sim \text { \$196 } \\
\text { Million }\end{array}$ & 2007 & $>12$ Months & 2350 & 130 & $\begin{array}{l}\text { Polar } \\
\text { Circular } \\
(200 \mathrm{~km})\end{array}$ & $\begin{array}{l}\text { 1) First mission in China's 3-stage lunar } \\
\text { exploration program } \\
\text { 2) To obtain 3-D streo images of lunar surface } \\
\text { and analyze elemental abundance }\end{array}$ \\
\hline 4 & CHANDRAYAAN- 1 & ISRO, India & $\begin{array}{l}\sim 88.6 \\
\text { Million }\end{array}$ & \begin{tabular}{|l} 
Early \\
2008 \\
\end{tabular} & $\sim 24$ Months & 1050 & 55 & $\begin{array}{l}\text { Polar } \\
\text { Circular } \\
(100 \mathrm{~km})\end{array}$ & $\begin{array}{l}\text { 1) India's first deep space mission } \\
\text { 2) To carry instruments from NASA, ESA and } \\
\text { Belgium }\end{array}$ \\
\hline 5 & $\begin{array}{l}\text { LUNAR } \\
\text { RECONNAISSANCE } \\
\text { ORBITER (LRO) } \\
\end{array}$ & $\begin{array}{l}\text { NASA, United } \\
\text { States }\end{array}$ & $\sim \$ 400$ & $\begin{array}{l}\text { Oct. } \\
2008\end{array}$ & $>24$ Months & 1210 & 100 & $\begin{array}{l}\text { Polar } \\
\text { Circular } \\
(50 \mathrm{~km})\end{array}$ & $\begin{array}{l}\text { 1) First mission in NASA's Robotic Lunar } \\
\text { Exploration Program } \\
\text { 2) To carry LCROSS, an impactor as } \\
\text { secondary payload on the LRO mission }\end{array}$ \\
\hline 6 & LUNA-GLOB & $\begin{array}{l}\text { Roscosmos, } \\
\text { Russia }\end{array}$ & & 2012 & & & & $\begin{array}{l}\text { Penetrator- } \\
\text { Lander }\end{array}$ & $\begin{array}{l}\text { 1) To deploy } 13 \text { seismic probes across } \\
\text { diverse regions of the Moon } \\
\text { 2) To test presence of volatiles including } \\
\text { water in the polar region }\end{array}$ \\
\hline
\end{tabular}

Source: International Space Agencies. 


\section{NASA's Robotic Lunar Exploration Program}

In support of NASA's Vision for Space Exploration that calls for undertaking lunar exploration activities to enable sustained human and robotic exploration of Mars and beyond, the Robotic Lunar Exploration Program (RLEP) has been instituted. The RLEP is responsible for executing a series of robotic missions to the Moon to conduct research and prepare for future human exploration.

The primary purpose of RLEP is to reduce risk, enhance mission success, and reduce the cost of human missions, as well as to enable the scientific activities human explorers will undertake on the Moon. These objectives will be accomplished by designing and implementing a program of robotic lunar missions to collect critical measurements, demonstrate key technologies, and emplace essential infra structure, while also seeking to make discoveries about what the Moon can offer as a scientific stepping-stone to Mars and beyond. The role of the RLEP is to ensure that all lunar flight missions are integrated into a program in a manner that allows them to achieve mission success, and support the larger goal of integrated human and robotic exploration.

The RLEP goals are as follows:

- Provide early information for human missions to the Moon.

- Evolvable to later human systems.

- Make exploration more capable and sustainable.

- Key requirements involve establishment of

- $\quad$ Terrain and surface properties

- Knowledge of polar regions

- Support infrastructure

- $\quad$ Provides major scientific and exploration benefit by 2009.

- LRO launch planned for October 2008; one-year mission

- Selected instruments to complement other foreign efforts ${ }^{2}$

The first RLEP mission is the Lunar Reconnaissance Orbiter (LRO) currently in development. LRO is designed to provide high resolution mapping and photography of the Moon's surface in order to identify potential future landing sites, and probable distribution of lunar resources.

LRO contains a suite of six instruments selected based on a competitive process, plus a technology demonstration payload that offers additional measurement data. These instruments include: a Lunar Orbiter Laser Altimeter and LRO Camera for high resolution imaging of the lunar surface; a Lunar Exploration Neutron Detector to search for evidence of water ice; a Diviner Lunar Radiometer to map the temperature of the lunar surface; a Lyman-Alpha Mapping sensor to observe the lunar surface in the far ultraviolet; and, a Cosmic Ray Telescope to measure the Moon's radiation environment and assess its potential impact on biological tissue. ${ }^{3}$

One of the LRO instruments, the Lunar Exploration Neutron Detector (LEND), is to aid in the global search of hydrogen distribution through 1-2 meters of lunar subsurface from $50 \mathrm{~km}$ circular polar orbit of LRO. The most important property of LEND is its capability to provide high spatial resolution mapping of epithermal neutrons with collimated neutron detectors. LEND is able to detect hydrogen-rich spot at a pole with 100ppm of hydrogen with spatial resolution of $5 \mathrm{~km}$ and to produce global mapping of hydrogen content with resolution of $5-20 \mathrm{~km}$. The LEND is a Russian made and Russian supplied instrument similar to the High Energy Neutron Detector (HEND) that Russia provided as a science instrument onboard NASA's Mars Odyssey probe. Data from LEND with high spatial resolution could help to distinguish polar spots with enhancement of implemented hydrogen in the regolith from cold traps with water ice deposits. ${ }^{4}$

NASA has selected the Lunar CRater Observation and Sensing Satellite (LCROSS) as the secondary payload for the LRO mission. After launch, the secondary payload LCROSS spacecraft will arrive in the lunar vicinity independent of the LRO satellite on the way to the Moon, the LCROSS spacecraft's two main parts, the Shepherding Spacecraft (S-S/C) and the Earth Departure Upper Stage (EDUS), will remain coupled.

As the spacecraft approaches the Moon's south pole, the upper stage will separate, and then will impact a crater in the south pole area. A plume from the upper stage crash will develop as the Shepherding Spacecraft heads in toward the Moon. The Shepherding Spacecraft will fly through the plume, and instruments on the spacecraft will analyze the cloud to look for signs of water and other compounds. Additional space and Earth-based instruments also will study the 2.2-million-pound (1000-metric-ton) plume. Then the Shepherding Spacecraft itself will become an impactor, creating a second plume visible to lunar-orbiting spacecraft and Earth-based observatories. 
NASA has conceived the second RLEP mission as the first lunar lander that will build upon the knowledge gained, assets and infrastructure deployed from LRO. It will have two broad primary objectives namely, mapping of the light (power) "resource" at locations of interest and to search for water ice.

The RLEP-2 lander mission has the following investigation topics as the areas of interest:

- Lunar environment - impact on Human Performance and Safety

- Volatile Inventory and Characterization

- Geotechnical measurements

- Regolith flow and manipulation

- Multi-phase fluid dynamics

- Precision Landing and Hazard Avoidance

- ISRU Demonstrations/Technology Development ${ }^{5}$

NASA aims to utilize the RLEP missions (2008-2015) and planned future Lunar Human Exploration Program (2015-2030) as an important opportunity in gaining operational experience required for a Mars Human Exploration Program. In-situ, resource utilization is an important technology that should be tested on lunar missions. Raw materials handling, specific refinement processes, end-product handling, and use in shielding and general operations are examples for aspects of in-situ resource utilization that are similar enough on both bodies to warrant lunar rehearsal. Several psychosocial factors impacting the success of a long-duration human mission to Mars can be best examined through Moon missions since they include the two crucial stressors of complete isolation and reduced gravity. Additionally medical infrastructure and procedures that will be affected by reduced surface gravity and/or associated physiological changes have to be developed and tested. The resulting knowledge base of infrastructure, procedures and techniques are required for crewmember selection and psycho-social factors consideration as well as for training to conduct a human Mars mission. ${ }^{6}$

The NASA annual budget for the Robotic Lunar Exploration Program (RLEP) is provided below.

\begin{tabular}{|l|l|l|l|l|l|l|l|}
\hline RLEP & FY2005 & FY2006 & FY2007 & FY2008 & FY2009 & FY2010 & FY2011 \\
\hline $\begin{array}{l}\text { Budget } \\
\text { (\$, Millions) }\end{array}$ & 51.6 & 134.3 & 272.7 & 366.9 & 411.3 & 421.0 & 414.5 \\
\hline
\end{tabular}

Source: President's FY2007 Budget Request, NASA.

\section{EUROPEAN SPACE AGENCY'S SMART-1 MISSION}

Europe's first mission to the Moon is SMART-1. It is also first of the Small Missions for Advanced Research in Technology of ESA's Horizons 2000 science plan. Its principal mission is to demonstrate innovative and key technologies for deep-space science missions. Its primary objective is to flight test Solar Electric Primary Propulsion (SEPP) for future large missions.

The SMART-1 spacecraft was launched on 27 September 2003, as Ariane-5 auxiliary passenger and injected into GTO (Geostationary Transfer Orbit). SMART-1 science payload, with a total mass of some $19 \mathrm{~kg}$, features many innovative instruments and advanced technologies. The payload comprises seven instruments addressing technological aspects related to the electric propulsion and plasma environment (EPDP, SPEDE), spacecraft deep space communication (KaTE), lunar science (D-CIXS, AMIE, SIR) and astronomy and solar observations (XSM). ${ }^{7}$

The European Space Agency (ESA) states the following as the SMART-1 Technology and Science goals:

- test SEPP and characterize the induced environment

- test new spacecraft and payload technology for cornerstone missions

- moon elemental geochemistry and mineralogy

- moon geology, morphology \& topography at medium- \& high-resolution

- moon exospheric and polar environment and

- cruise observations of X-ray cosmic sources ${ }^{8}$

One of the major objectives of SMART-1 mission is to confirm exactly how the Moon was formed. The most widely accepted theory is that a Mars sized object collided with Earth more than 4 billion years ago and that Moon was formed out of the debris. An alternative theory is that the Moon is a lump of rock captured by the Earth's gravity.

The D-CIXS (Demonstration of a Compact Imaging X-ray Spectrometer) instrument is a key component which is used to provide the first global map of the lunar surface's composition and will enable scientists to draw up new three-dimensional models of the landscape. The analysis of D-CIXS data sent thus far already revealed the presence of calcium. It will take another year for scientists to fully analyze the data sent by SMART-1 instruments and draw some conclusions about the origins of the Moon. 
The XSM solar X-ray monitor also performed spectrometric observations of the sun during the cruise. The Advanced Moon Micro-Imager (AMIE) instrument has helped to validate deep-space optical communications (LaserLink Experiment) using ESA's Optical Ground Station at the Teide Observatory in Tenerife. The camera also validated the OBAN autonomous navigation experiment based on image processing.

The SIR is a spot spectrometer that will obtain high-spectral-resolution (6-nanometer) spectra in the $0.9-2.4-$ micrometer range with spatial resolutions as high as 300 meter/pixel. This spatial resolution is high enough to sample typical-sized homogeneous areas on the Moon. The spectral range covered includes diagnostic features of key lunar minerals. The quoted goals of this instrument include looking at compositional variations in the lunar highlands, mineralogical analysis of complex impact craters, and detailed analysis of space weathering effects.

The innovative SMART-1 mission's completion came with a fiery crash of the probe into the Moon's nearside on September 3, 2006. The impact site put it in the Moon's mid-southern latitudes in a region known as the Lake of Excellence. The location is believed to be of mostly volcanic origin and areas of highlands and hills are also nearby. Larger telescopes detected a flash at the moment of impact due to vaporized hydrazine fuel. If the debris reaches an altitude of over 12 miles, it could be lit by sunlight. The material propelled into sunlight will be closely analyzed to determine details such as its mineral composition and physical properties. Some of the debris could be excavated from underground during SMART-1's crash, so scientists are especially interested in learning about the sub-surface of the Moon. ${ }^{9}$

SMART-1 is also a first very low-budget small mission for science at ESA and in this sense it explores and tests new ways of implementing cost-effective procurement and efficient management. The total cost for the SMART-1 mission is estimated at about 150 million euros at 2001 economic conditions including launch, payloads and operations for the duration of the mission's life.

The Aurora program, Europe's framework for space exploration, is currently being executed by ESA as a building block in a broader international effort for the robotic and human exploration of Mars, with the Moon as an important stepping stone. The core program as part of the Aurora program includes mission architectures for human and robotic missions to the Moon and the Mars. ESA has envisioned international cooperation as a key enabling element to achieve the long term goals of the Aurora program. ${ }^{10}$

\section{RUSSIAN LUNA-GLOB PROJECT}

Russia, which pioneered the robotic exploration of the Moon is planning an ambitious project conceived with a view to understand the origin of the Earth-Moon system. The new "Luna-Glob" mission is a formal part of the Russian space plan with launch set for 2012 subject to future budget and technical risks. The Russian lunar mission is to follow the launch in 2009 of a Russian sample return flight to the Martian moon Phobos as part of a renewal of Russian robotic planetary exploration.

The Luna-Glob initial design plan includes a lunar orbiter that will simultaneously deploy 13 probes across diverse regions of the lunar surface. This will include two penetrators that will be fired toward the Apollo 11 and Apollo 12 landing sites to acquire subsurface data to build on the manned exploration and instrumentation left at those locations 37 years ago by U.S astronauts. The probe is also to shower 10 other higher-speed penetrators on the Moon that will form a seismic network to help solve questions about the Moon's origin.

The mother ship for the penetrators is then to drop a soft lander into a south polar crafter to search for signs of water ice that would complement data from the planned 2008 U.S. Lunar Crater Observation and Sensing impactor mission to the same region.

The first science objective of the Luna-Glob project is to conduct seismic experiments, which would allow us t get information on the internal structure of the Moon. This is proposed to be carried out through two types of seismic experiments:

- Small aperture seismic array with high-speed penetrators (HSP) and

- Broadband seismometery (penetrator-landers, PL)

The second objective of the Luna-Glob mission is to test the presence of volatiles including water in the polar regions of the Moon. In order to study the concentration of volatiles supposedly present in the permanently shadowed lunar polar regions, soft landing of the analytical station containing a mass-spectrometer and neutron spectrometer combined with seismic station has been proposed. ${ }^{11}$

Luna-Glob is planned to be launched using either the 'Molnia' or 'Soyuz' rockets. Duration of the flight to the Moon is estimated to be 4.5 days. Twenty-nine hours before arriving at the Moon after correction and reorientation 
of the spacecraft, the HSP carrying cassette is detached from the spacecraft. Then after reorientation, the first penetrator-lander, and after reorientation, the second penetrator-lander are detached.

After releasing the HPL and PL, the spacecraft is injected into a polar circular orbit, selected to pass over the landing site $\mathrm{f}$ the polar station. The PS is detached from the spacecraft and decelerated to zero orbital speed. It descends to an altitude of about $2 \mathrm{~km}$, where the braking engines decrease the vertical speed to zero. The braking engines are ejected and the station touches the lunar surface with a speed of $5-25 \mathrm{~m} / \mathrm{s} .{ }^{12}$

The successful deployment and realization of the scientific objectives of the proposed Luna-Glob mission would result in a significant breakthrough in geosciences and planetology. It is hoped that after decades of stagnation of the planetary research program in Russia, it will receive a fillip with the successful completion of the Luna-Glob mission. This experience could be helpful in collaborating with countries now planning their first lunar expeditions such as Japan, China and India.

\section{JAPANESE LUNAR EXPLORATION PROGRAM}

The Japanese Aerospace Exploration Agency (JAXA) unveiled its 20-year plan called "JAXA 2025 Vision" in April 2005, in which five priorities were set for the next wave of space programs. One of the proposed agendas is to build a lunar base and populate it with advanced robotics by around 2025 .

As a first step in its ambitious lunar exploration program, JAXA plans to launch the Lunar Explorer, SELENE (SELenological and ENgineering Explorer), from Tanegashima Space Center in 2007 using an H-IIA Launch Vehicle. The science topics to be studied by using SELENE data are surface composition of chemistry and mineralogy, evolution tectonics of surface including subsurface to $5 \mathrm{~km}$ depth, gravity field of whole moon and magnetic field distribution for the study on origin and evolution of the Moon. SELENE will investigate the entire moon in order to obtain information on its elemental and mineralogical composition, its geography, its surface and sub-surface structure, the remnant of its magnetic field, and its gravity field. The results are expected to lead to a better overall understanding of the Moon's evolution. The observation equipment installed on the orbiting satellite will observe plasma, the electromagnetic field and high-energy particles. ${ }^{13}$

SELENE's configuration and consists of the Main orbiter and two small satellites (Relay Satellite and VRAD Satellite). The Main Orbiter will reach the vicinity of the Moon. Once it has reached the Moon, it will be placed into an peripolar orbit at an altitude of $100 \mathrm{~km}$. The Relay Satellite will be placed in an elliptic orbit at an apogee of 2400 $\mathrm{km}$, and will relay communications between the Main orbiter and ground station. The VRAD Satellite will play a significant role in measuring the gravitational field around the Moon. The Main Orbiter will be employed for about one year and will observe the entire Moon.

SELENE carries 14 science instruments onboard to carryout remote sensing of the lunar surface. The science instruments selected are X-ray Spectrometer (XRS), Gamma-ray Spectrometer (GRS), Multi-band imager (MI), Spectral Profiler (SP), Terrain Camera (TC), Lunar Radar Sounder (LRS), Laser Altimeter (LALT), Differential VLBI Radio Source (VRAD), Relay Satellite Transponder (RSAT), Lunar Magnetometer (LMAG), Charged Particle Spectrometer (CPS), Plasma Analyzer (PACE), Radio Science (RS), and Plasma Imager (UPI). ${ }^{14}$

Among the various planned international missions to the Moon SELENE's unique contributions will be its observations of the Moon's sub-surface structure, its gravity field and the remnant of its magnetic field. Japan is also planning a follow-on mission, SELENE-B that would perform pin-point soft landing near a central hill inside a crater to perform autonomous exploration on the planetary surface for in-situ study of its geology. ${ }^{15}$

JAXA is also currently planning a LUNAR-A mission, Japanese Penetrator Mission, to explore the lunar interior by seismic and heat-flow experiments. Two penetrators containing two seismometers (horizontal and vertical components) and heat-flow probes will be deployed from a spacecraft onto the lunar surface, one on the near-side and the other on the far-side of the moon. The data obtained by the penetrators will be transmitted to the earth station via the Lunar-A mother spacecraft orbiting at an altitude of about $200 \mathrm{~km}$.

The Lunar-A spacecraft will be inserted into an elliptic lunar orbit, after about a half-year cruise during which complex maneuvering is made using the lunar-solar gravity assist. After lunar orbit insertion, two penetrators will be separated from the spacecraft, one by one, and will be landed on the lunar surface. The seismic observations by the penetrators are expected to provide key data on the size of the lunar core, as well as data on deep lunar mantle structure. The heat flow measurements at two penetrator-landing sites will also provide important data on the thermal structure and bulk concentrations of heat-generating elements in the Moon. These data will provide much stronger geophysical constraints on the origin and evolution of the Moon than has been obtained so far. This mission will also demonstrate the usefulness of the penetrator technology for future planetary missions. ${ }^{16}$

Moon is considered an ideal location for observing the solar system, Earth and the universe because there is no atmospheric interference, no artificial light and electro-magnetic noises. JAXA is working on establishing the 
fundamental technologies required for lunar observations stations, and on developing observation devices that can withstand the severe lunar environment.

JAXA's long term plan for lunar exploration envisages sending an unmanned spacecraft that will land on the moon and the probe ship that will collect and return lunar samples by 2020 and construction of a human exploration base on the lunar surface to be completed by 2030 .

\section{CHINA'S CHANG'E PROGRAM}

China is embarking on an ambitious lunar exploration program a-s part of its new initiative on deep space missions. The primary objectives of the Chinese deep space missions are to study the distribution and utilization of lunar resources and terrestrial planetary science as well as exploring scientific measures for supporting mankind's sustainable survival on Earth.

The Chinese lunar exploration project is known as the Chang' $E$ Project named after an ancient Chinese legend about a beautiful young fairy who took a magic potion, flew to the Moon, and stayed there as Goddess of the Moon. China plans to implement its first lunar exploration mission Chang'E-1 by 2007. Chang'E-1 is a three-axis stabilized lunar satellite, with a mass of over $900 \mathrm{~kg}$ and a payload of four instruments. The spacecraft will operate in a polar orbit at a working altitude of $200 \mathrm{~km}$ above the surface of the Moon for a year. The mission objectives are

- to obtain a three-dimensional stereo image of the lunar surface,

- to determine distribution of some useful elements and to estimate their abundance,

- to survey the thickness of lunar soil and to evaluate resource of ${ }^{3} \mathrm{He}$ and

- to explore the environment between the Moon and Earth. ${ }^{17}$

To achieve the above mission goals, five types of scientific instruments are selected as payloads of the lunar craft. These include stereo camera and spectrometer imager, laser altimeter, microwave radiometer, gamma and Xray spectrometers and space environment monitor system. In order to collect, process, store and transmit the scientific data of various payloads a special payload data management system is also included. The space operation for China's first lunar exploration program, Chang'E-1 will be provided by the S-band aerospace Telemetry, Tracking and Command (TT\&C) network designed for China's manned space program. China's deep space network includes a 50 meter antenna located in Beijing and a 40 meter antenna located in Yunnan province.

The second phase of the Chang'E program consists of a lander-rover stage that is planned to be launched in 2012 to conduct exploration on the surface through the soft landing of a detector. The rover would consist of a camera, a telescope and seismological instruments to register quake activities on the moon. The scientific objectives envisaged are as follows:

- to study the topography and selenology in the landing and roaming areas ( 10km radius)

- to conduct in-situ measurements of lunar minerals and resources, and to survey the composition of surface materials

- to probe the interior of the moon and

- to study the space environment and perform moon-based astronomy. ${ }^{18}$

The third phase of the Chang'E program consists of a sample return stage that is planned to be carried out before 2020. It is planned to survey the lunar surface, collect some lunar samples and return to the Earth for further analysis. The preliminary scientific objectives are as follows:

- to return to earth lunar specimen sampled by drilling and collecting and to study the returned samples systematically

- to study the extraction of resource materials and probe lunar dynamics in deep interior

- to investigate mineralogy, petrology and selenochemistry of the returned samples, and study the evolution of the Moon and Earth-Moon system and

- to conduct long-term moon-based selenology, space science and astronomy. ${ }^{19}$

According to the China National Space Administration (CNSA), the Chinese lunar exploration program is open to international co-operation. But, the first phase of the program, Chang'E-1 orbiter, is being solely accomplished by China through its own technology, products and designs. A Sino-European collaboration to develop a potential payload element for the Chang'E-2 is under study. The planned instrument suite is called the Peripatetic Scientific Tools for Lunar Exploration (PESTLE). PESTLE can contribute to a geological evolution of the Chang'E-2 landing area with implications for lunar origin and history. It can also be used to assess the availability of the lunar resources at the landing site. The PESTLE instrument suite offers an opportunity to form an European Space Agency - China 
collaboration to build on the success of Double star satellite system within the context of the Aurora program. China has also expressed interested in collaborating with the other international lunar exploration missions.

The CNSA has earmarked about 1.6 billion Yuan (\$196 million) for the Chang'E-1 project.

\section{INDIA'S CHANDRAYAAN-1 MISSION}

The Indian Space Research Organization (ISRO) has started a new initiative to launch dedicated scientific satellites assigned for planetary exploration, astronomical observation and space atmospheric sciences. The Chandrayaan-1 mission to Moon is the first planetary exploration mission of this new initiative. The first lunar mission Chandrayaan-1, a $525 \mathrm{~kg}$ satellite is being proposed to be a long duration ( 2 years), low altitude (100 km) polar orbiter mission. ${ }^{20}$ Chandrayaan-1 is planned for launch in early 2008 on board India's Polar Satellite Launch Vehicle.

The scientific objectives of the Chandrayaan-1 are simultaneous geochemical, mineralogical and photogeological studies of the whole lunar surface. A suite of baseline payloads, identified to meet this scientific objective, include a Terrain Mapping Camera (TMC), a Hyper-Spectral Imager (HySI), a low Energy X-ray Spectrometer (HEX) and a Lunar Laser Ranging Instrument (LLRI). These payloads will provide simultaneous mineralogical, chemical and photogeological mapping of the lunar surface at resolutions better than previous and currently planned lunar missions. They will allow (i) direct estimation of lunar surface concentration of the elements $\mathrm{Mg}, \mathrm{Al}, \mathrm{Si}, \mathrm{Ca}$, Ti and Fe with high spatial resolution $(<=20 \mathrm{~km})$, (ii) High resolution $(\sim 100 \mathrm{~m})$ UV-VIS-NIR mapping of the lunar surface to identify abundances of various lunar minerals, (iii) High resolution 3D mapping of the lunar surface, and (iv) nature of volatile transport on moon, particularly to colder lunar polar regions. ${ }^{21}$

One of the significant scientific instrument to be carried onboard Chandrayaan-1 is the Moon Minerology Mapper (M3, or "m-cube"). M3 is a state of the art mapping spectrometer developed by NASA. The primary science goal of M3 is to characterize and map lunar surface mineralogy in the context of its geologic evolution. Of the various missions and instruments that will reopen exploration of the Moon, only the M3 will both characterize and map the mineralogy of the Moon in geologic context at high spatial resolution. In addition to exploring the global mineralogy of the Moon for the first time from orbit, M3 is designed to address the issue of whether the Hydrogen detected by earlier missions at the poles is in the form of water ice. ${ }^{22}$

The Chandrayaan-1 is also planned to include an impactor carrying a high sensitive mass spectrometer, a video camera and a radar altimeter. The impactor will be released once the lunar orbiter arrives at the designated orbit to land it at the predetermined location on the lunar surface. Apart from the video imaging of the impact site, the onboard mass spectrometer will try to detect possible presence of trace gases in the lunar exosphere.

As a follow-up to the Chandrayaan-1 mission, India is exploring preliminary studies on mission to the Mars, Venus, fly by to asteroids and comets. As part of this study, landing a craft on the surface of the moon is also being explored. While ISRO currently has the capability to explore the inner solar system, it needs significant technological development in various areas covering sensor and instruments, spacecraft resources, communication, navigation and thermal management, robotics and rover design.

The Chandrayaan-1 mission is allocated a total of $\$ 88.6$ for the entire project, including design, development and launch of the satellite by an advanced version of an Indian PSLV. The development of a Deep Space Network (DSN) in Bangalore consisting of a 35m diameter antenna is underway for download of data from the lunar orbiter but is also an asset for future Indian deep space missions. ${ }^{23}$

India' first mission to the moon is truly an international cooperation venture as ISRO planned from the beginning of the project to allocate about $10 \mathrm{~kg}$ of payload out of the total $60 \mathrm{~kg}$ of payload mass for foreign instrument that would compliment the primary Indian instruments of the Chandrayaan-1 spacecraft. Over a dozen proposals for participation were received by ISRO but only six were accepted on the merit of being complementary to the basic objective of the mission.

On June 27, 2005 the European Space Agency (ESA) and ISRO signed an agreement for including European instrument onboard India's Chandrayaan-1 lunar orbiter mission. Under the agreement, Europe will potentially coordinate and support the provision of three instruments: CIXS-2, the Chandrayaan-1 Imaging X-Ray Spectrometer; SARA, a sub-kev atom reflecting analyser; and SIR-2, a Near-Infrared Spectrometer. It will also contribute to the hardware for the High-Energy X-ray Spectrometer (HEX). Chandrayaan-1 will also carry a radiation dose monitor (RANDOM) from the Bulgarian Academy of Sciences. ESA and ISRO also will share the data resulting from their respective experiments. ${ }^{24}$

ISRO chief Mr. G.Madhavan Nair and NASA administrator Dr. Michael Griffin signed a memorandum of understanding to include two American advanced scientific instruments on May 9, 2006 during Dr. Griffin's visit to India. The instruments are a Mini Synthetic Aperture Radar (Mini SAR) developed by the Applied Physics 
Laboratory at John Hopkins University and funded by NASA, and the Moon Minerology Mapper jointly built by Brown University and NASA's Jet Propulsion Laboratory. ${ }^{25}$

Chandrayaan-1 can be seen as a technology and science demonstrator for future Indian planetary and science missions and as a precursor for a road map of robotic and human exploration of the Moon and inner solar system by ISRO.

\section{Conclusion}

This paper discussed a short review of the various lunar exploration missions currently being undertaken by the international space agencies. The paper also brought out the different policy goals and programs, scientific objectives, economics and international cooperation among these missions.

Despite having nationalistic lunar exploration goals as part of their broader space exploration and space policy goals, the leading space agencies are discussing collaboration through organizations such as the International Lunar Exploration Working Group. Many bilateral agreements are also being pursued by the international space agencies to optimize utilization of resources and expertise.

\section{References}

${ }^{1}$ Paul Guinnessy, "Countries Race to Launch Moon Missions”, Physics Today, February 2005.

${ }^{2}$ James Watzin, "An Introduction to the Robotic Lunar Exploration Program (RLEP)," $43^{\text {rd }}$ Goddard Memorial Symposium, March 2005.

${ }^{3}$ J. Garvin, et al., "Lunar Reconnaissance Orbiter Overview: The Instrument Suite and Mission”, Lunar and Planetary Science Conference XXXVII, 2006.

${ }^{4}$ I.G. Mitrofanov, "Lunar Exploration Neutron Detector Onboard LRO Mission”, Space Resources Roundtable VII, 2005

${ }^{5}$ NASA Framework for the Future, "RLEP 2 Lander Mission", MSFC/GSFC/APL, February 2006.

${ }^{6}$ Scott Horowitz, "Lunar Exploration Strategy Workshop - RLEP", NASA Exploration Systems Mission Directorate, April 2006

${ }^{7}$ G.D. Racca, et al, "Europe to the Moon: SMART-1 Final Preparation for Launch", 54 ${ }^{\text {th }}$ International Astronautical Congress of the International Astronautical Federation, IAC-03-IAA.11.3.03, October 2003.

${ }^{8}$ Benjamin Bussey, "SMART-1: Europe at the Moon", Lunar and Planetary Information Bulletin, Lunar and Planetary Institute, February 2005

${ }^{9}$ European Space Agency, "Impact landing ends SMART-1 mission to the Moon”, ESA News, September 3, 2006.

${ }^{10}$ Piero Messina, et al., “The Aurora Programme - Europe's Framework for Space Exploration”, ESA Bulletin 126, European Space Agency, May 2006

${ }^{11}$ E.M. Galimov, "Luna-Glob project in the context of the past and present lunar exploration in Russia", Journal of Earth Systems Science, Vol. 114 No.6, pp. 801-806, December 2005

${ }^{12}$ Craig Covault, "Russia Plans Ambitious Robotic Lunar Mission”, Aviation Week and Space Technology News, June 2006

${ }^{13}$ Kai Matsui, et al., "Japan's Moon Exploration - First Lunar Resources Utilization Workshop”, Space Resources Roundtable VII, 2005.

${ }^{14}$ M. Kato, et. al, "SELENE, The Japanese Lunar Orbiting Satellites Mission: Present Status and Science Goals", Lunar and Planetary Science Conference XXXVII, 2006.

${ }^{15}$ JAXA, "SELenological and Engineering Explorer "SELENE”, URL: http://jaxa.jp/missions/projects/sat/exploration/selene/

${ }^{16}$ H. Mizutani, et al., "Lunar-A mission: Outline and current status", Journal of Earth Systems Science, Vol. 114 No.6, pp. 763-768, December 2005

${ }^{17}$ Sun Huixian, et al., "Scientific Objectives and payloads of Change'E-1 lunar satellite", Journal of Earth Systems Science, Vol. 114 No.6, pp. 789-794, December 2005

${ }^{18,}{ }^{19}$ Maohai Huang, "China's Lunar Exploration Programme and NAOC involvement", UK-China Workshop on Astronomy, Beijing, September 2005.

${ }^{20}$ J.N. Goswami, et al., "Chandrayaan-1: Indian Mission to the Moon", Lunar and Planetary Science Conference XXXVII, 2006.

${ }^{21}$ Bernard H. Foing, "The case for the first Indian robotic mission to the Moon", Current Science, Vol. 87, No.8, Indian Institute of Science, Bangalore, October 2004.

${ }^{22}$ Carlé Pieters, et al., "Global Mineralogy of the Moon: A cornerstone to Science and Exploration", Lunar and Planetary Science Conference XXXVII, 2006.

${ }^{23}$ Notes on Demands for Grants, "The Budget Allocation for Department of Space Activities", Demand No\# 88, Government of India, URL: http://indiabudget.nic.in/ub2006-07/ed/sbe88.pdf [cited April 2006]

${ }^{24}$ European Space Agency, “Agreement signed for European instruments on Chandrayaan-1", ESA News, July 1, 2005.

${ }^{25}$ NASA Exploration Mission Directorate, "NASA to work with India on Moon Mission”, NASA News, May 9, 2006. 